\title{
Goal-Congruent Default Network Activity Facilitates Cognitive Control
}

\author{
R. Nathan Spreng, ${ }^{1,2}$ Elizabeth DuPre, ${ }^{1}$ Dhawal Selarka, ${ }^{4}$ Juliana Garcia, ${ }^{1}$ Stefan Gojkovic, ${ }^{4}$ Judith Mildner, ${ }^{1}$ \\ (D)Wen-Ming Luh, ${ }^{3}$ and Gary R. Turner ${ }^{4}$ \\ ${ }^{1}$ Laboratory of Brain and Cognition, Department of Human Development, ${ }^{2}$ Human Neuroscience Institute, and ${ }^{3}$ Cornell MRI Facility, Cornell University, \\ Ithaca, New York 14853, and ${ }^{4}$ Department of Psychology, York University, Toronto, Ontario, M3J1P3, Canada
}

\begin{abstract}
Substantial neuroimaging evidence suggests that spontaneous engagement of the default network impairs performance on tasks requiring executive control. We investigated whether this impairment depends on the congruence between executive control demands and internal mentation. We hypothesized that activation of the default network might enhance performance on an executive control task if control processes engage long-term memory representations that are supported by the default network. Using fMRI, we scanned 36 healthy young adult humans on a novel two-back task requiring working memory for famous and anonymous faces. In this task, participants (1) matched anonymous faces interleaved with anonymous face, (2) matched anonymous faces interleaved with a famous face, or (3) matched a famous faces interleaved with an anonymous face. As predicted, we observed a facilitation effect when matching famous faces, compared with anonymous faces. We also observed greater activation of the default network during these famous facematching trials. The results suggest that activation of the default network can contribute to task performance during an externally directed executive control task. Our findings provide evidence that successful activation of the default network in a contextually relevant manner facilitates goal-directed cognition.
\end{abstract}

Key words: cognitive control; default mode network; fMRI; long-term memory; n-back; working memory

\section{Introduction}

The default network is typically deactivated by tasks that require attention and cognitive control. Transient increases in default network activity predict performance errors (Weissman et al., 2006) and off-task behavior, such as mind-wandering (Mason et al., 2007; Christoff et al., 2009). Tasks that deactivate the default network typically use stimuli that minimally engage internal mnemonic representations or are devoid of personal significance (shapes, letters). In contrast, engagement of the default network is elicited by tasks that are self-referential, social, or access longterm memory representations (Andrews-Hanna et al., 2014). In these processes, action is often decoupled from perception and relies upon online representations rather than external stimuli (Smallwood et al., 2013a). Coactivation and coupling of default and executive regions is observed when goal-directed cognition is internally directed (Spreng et al., 2010). In most cognitive control studies, however, engagement of the default network is incongruent with task goals. It is unknown how the default network is

\footnotetext{
Received July 9, 2014; revised Aug. 20, 2014; accepted Sept. 8, 2014

Author contributions: R.N.S., W.-M.L., and G.R.T. designed research; R.N.S., E.D., D.S., J.G., J.M., and W.-M.L. performed research; D.S., S.G., and W.-M.L. contributed unpublished reagents/analytic tools; R.N.S., E.D., and J.M. analyzed data; R.N.S. and G.R.T. wrote the paper.

This work was supported in part by NIH Grant 1S10RR025145 and an NSERC Discovery Grant to GRT. We thank Dale Stevens and Karen Spreng for comments on the paper, and Kyle Kurkela for assistance with data analysis. The authors declare no competing financial interests.

Correspondence should be addressed to Dr R. Nathan Spreng, Laboratory of Brain and Cognition, Department of Human Development, Cornell University, Ithaca, NY 14853. E-mail: nathan.spreng@gmail.com.

DOI:10.1523/JNEUROSCI.2815-14.2014

Copyright $\odot 2014$ the authors $\quad 0270-6474 / 14 / 3414108-07 \$ 15.00 / 0$
}

modulated when cognitive control processes interact with longterm memory representations during an externally oriented goaldirected task.

We developed a novel working memory task, the "famous faces n-back," to transiently evoke default network activity in the context of a sustained cognitive control challenge. Famous faces were used to activate long-term memory representations and engage the default network, consistent with prior observations that viewing famous or familiar faces activates posterior cingulate cortex (PCC), medial prefrontal cortex (MPFC), and medial and lateral temporal lobes (Leveroni et al., 2000). In our two-back task, images of famous faces were embedded within sequences of anonymous face stimuli. Three conditions of interest comprised a three face stimuli series, or triplet. In the first, participants viewed three anonymous faces, with an anonymous face-match decision (AAA condition). In the second, a famous face was embedded between two anonymous faces, with an anonymous face-match decision (AFA condition). In the third triplet, an anonymous face was embedded between two famous faces, with a famous face-match decision (FAF condition). Holding working memory demands constant enabled us to directly examine the impact of familiarity (famous face identities) on performance, while investigating the impact of default network engagement in the context of an externally directed cognitive control task. In other words, we directly assessed the impact of the default network on behavior that is mediated by mnemonic representations.

We predicted better performance for the famous face relative to the anonymous face-match conditions, consistent with previ- 


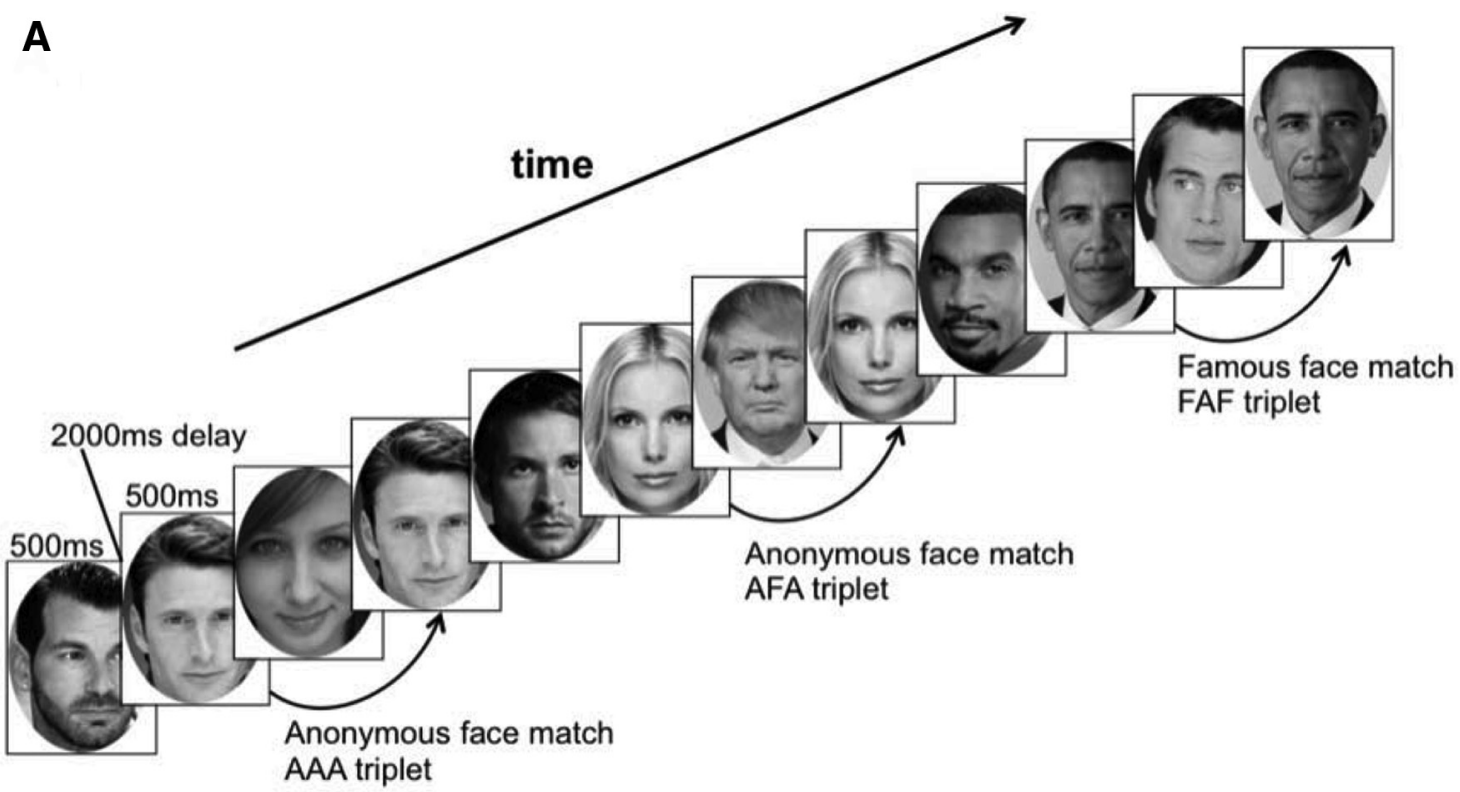

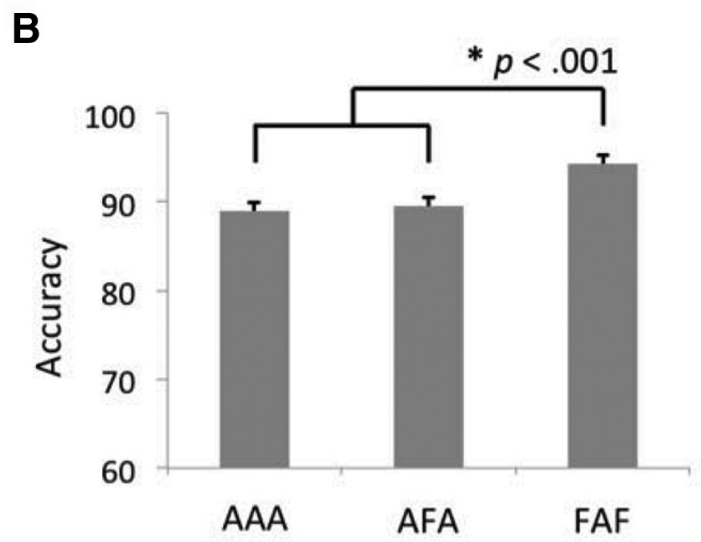

2-back triplets
C

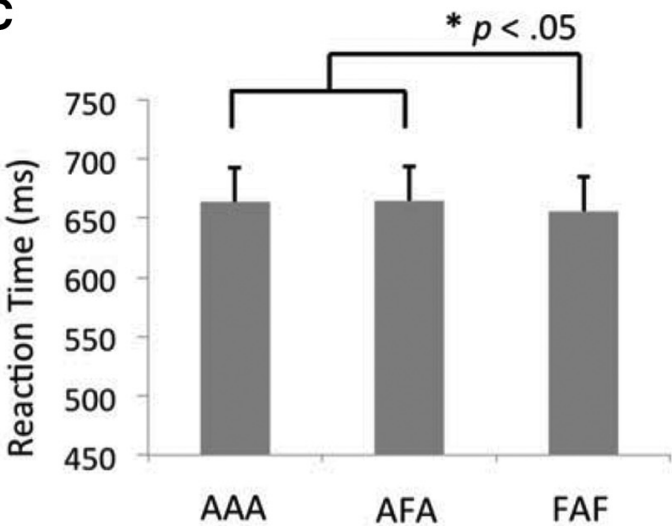

2-back triplets

Figure 1. Faces $n$-back task structure and performance. $A$, The faces two-back consisted of a stream of stimuli including famous and anonymous faces. Three triplet conditions were embedded within the task: AAA, AFA, and FAF. In the bottom, performance for the AAA, AFA, and FAF triplet matching for $(\boldsymbol{B})$ accuracy, and (C) RT for correct trials.

ous behavioral work (Jackson and Raymond, 2008). We predicted that this on-task behavioral facilitation would be accompanied by higher default network activity, providing critical evidence that task-relevant default network activation can facilitate cognitive control performance during an externally oriented task. Additional evidence comes from studies of resting-state functional connectivity, where individual differences in default network connectivity predicted externally directed information processing reliant on mnemonic representations (Baird et al., 2013; Smallwood et al., 2013b). Our predictions suggest that the impact of default network activation on cognitive control is dependent on whether access to stored representational knowledge is congruent with task goals, thereby influencing current actions.

\section{Materials and Methods}

Participants were 36 healthy young adults (mean age $=22.3$ years, $\mathrm{SD}=$ 3.8, 17 males and 19 females) with normal or corrected-to-normal visual acuity, and no history of psychiatric, neurological, or other medical illness that could compromise cognitive functions. All participants gave informed consent in accordance with the Institutional Review Board at Cornell University.
Faces two-back task. Stimuli consisting of famous and anonymous face images (Fig. 1) were presented serially and participants were asked to decide, for each face, whether it matched the face presented two images before (Fig. 1). Responses were made on a button box placed in the participant's right hand. Two blocks of 48 face images (famous to anonymous ratio $\sim 1: 3$ ) were presented during each run. Conditions of interest were the AAA, AFA, and FAF trial triplets, all of which were nonoverlapping and interleaved by anonymous faces. Faces were presented for $500 \mathrm{~ms}$, followed by $2000 \mathrm{~ms}$ fixation. Task blocks were preceded and followed by $30 \mathrm{~s}$ of fixation.

MRI data collection, preprocessing, and analysis. Brain imaging data were acquired with a 3T GE Discovery MR750 MRI scanner with a 32channel receive-only phased-array head coil at the Cornell Magnetic Resonance Imaging Facility, in Ithaca. Anatomical scans were acquired using a T1-weighted volumetric MRI magnetization prepared rapid gradient echo $\left(\mathrm{TR}=7.7 \mathrm{~ms}\right.$; $\mathrm{TE}=3.4 \mathrm{~ms} ; 7^{\circ} \mathrm{flip}$ angle; $1.0 \mathrm{~mm}$ isotropic voxels, 176 slices). Five $5 \mathrm{~m} 30 \mathrm{~s}$ experimental runs of blood-oxygen level-dependent (BOLD) functional scans were acquired with a $\mathrm{T} 2{ }^{*}$ weighted echo-planar imaging pulse sequence $(\mathrm{TR}=2500 \mathrm{~ms}$; $\mathrm{TE}=25$ $\mathrm{ms} ; 80^{\circ}$ flip angle; 49 axial slices; $3.0 \mathrm{~mm}$ isotropic voxels). Anatomical and functional scans were acquired with $2 \times$ acceleration with sensitivity encoding. 
All fMRI data were preprocessed using SPM8. The first four volumes in each run were excluded from analyses to allow for T1equilibration effects. Data were corrected for slice-dependent time shifts and for head motion within and across runs using a rigid body correction. Movement was plotted and visually inspected using ArtRepair (Mazaika et al., 2009); for four subjects, frames with movement $>0.5 \mathrm{~mm} / \mathrm{TR}$ were motion scrubbed, not exceeding $20 \%$ of data for any run. Images were then spatially normalized to the standard space of the Montreal Neurological Institute atlas and smoothed with a $6 \mathrm{~mm}$ full-width at half-maximum Gaussian kernel, yielding a volumetric time series resampled at $2 \mathrm{~mm}^{3}$ voxels.

The preprocessed neuroimages were analyzed with partial least squares (PLS; Krishnan et al., 2011). PLS is a data-driven multivariate statistical technique that reveals activity across the entire brain that correlates with study design. With this method, the hemodynamic response is not explicitly modeled. For the novel famous face analysis, the first instance of each famous face was examined as an event with a four-lag interval (10 s) to estimate the full hemodynamic response. For the working memory analyses, condition-wise triplets (AAA, AFA, FAF) were examined as trial blocks with a $15 \mathrm{~s}$ duration to account for the hemodynamic delay. Within PLS, the covariance between the design and all other brain voxels is decomposed into latent variables (LVs) that can identify multiple patterns of activity. The results provide a set of brain regions wherein activity is reliably related to the task conditions for each LV. Each brain voxel is given a singular value weight, known as a salience, which is proportional to the covariance of activity with the task contrast on each LV. Multiplying the salience by the BOLD signal value in that voxel and summing the product across all voxels gives a composite brain activity score for each participant on a given LV. These scores can be used to examine similarities and differences in brain activity across conditions, as greater activity in brain areas with positive (or negative) weights on an LV will yield positive (or negative) mean scores for a given condition. Confidence intervals (95\%) for the mean composite brain activity score in each condition were calculated from the bootstrap, and differences in activity between conditions were determined via a lack of overlap in these confidence intervals. The decomposition and associated resampling techniques consider all voxels simultaneously, thus avoiding the problem of multiple statistical comparisons. Because of its ability to identify voxels with covarying activity, this technique is methodologically suited to the investigation of large-scale brain networks. Significance of the LVs was determined by 500 permutation tests, using resampling without replacement. Robustness of each voxel's contribution to a LV was provided by bootstrapping that resampled the data 100 times, with replacement, to estimate the SE of the salience of each voxel on the LV. A bootstrap ratio (BSR), calculated as the ratio of each salience to its SE, was thresholded at \pm 2.58 , equivalent to $p<0.01$.

\section{Results}

Behavior

Task performance on the AAA, AFA, and FAF conditions, measured as accuracy and reaction time (RT), are depicted in Figure 1. We confirmed that accuracy was below ceiling for all three

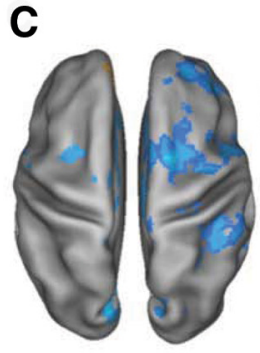

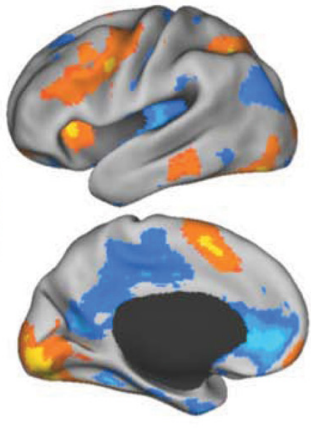
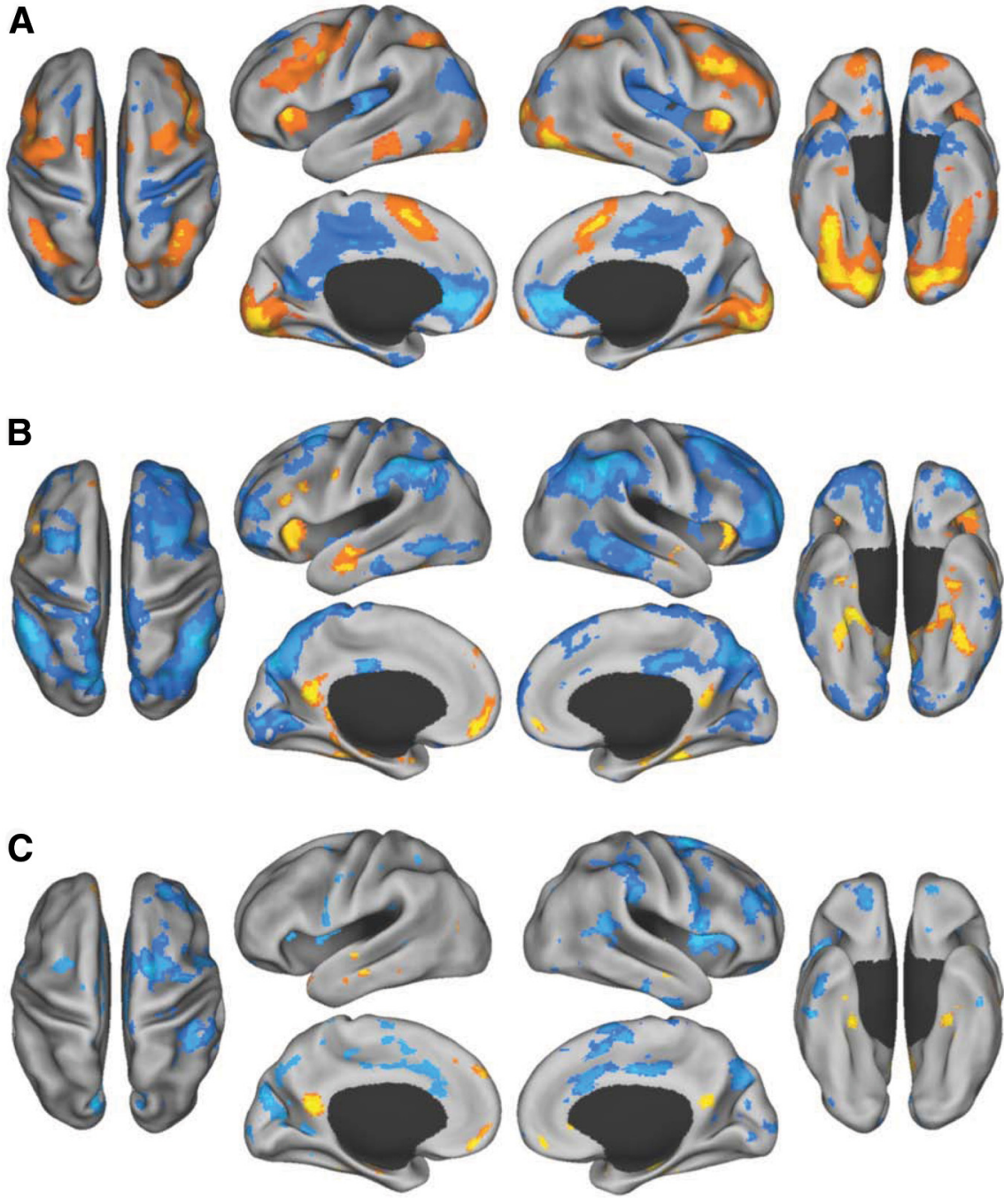

Figure 2. Sustained and transient brain activity during the faces n-back task. $A$, Sustained block activity for the faces n-back task (warm colors) and fixation (cool colors). B Transient activity during the first instance of viewing a famous (warm colors) versus anonymous (cool colors) face. $\boldsymbol{C}$, Transient activity during the triplets for famous face matching (warm colors) and anonymous face matching (cool colors) conditions.

conditions with a simple $t$ test criterion set to $100 \%$ (all $t$ values $<-6.3$, all $p$ values $<0.001$ ). As predicted, participants performed better when matching famous faces (FAF), compared with matching anonymous faces (AAA, AFA). A priori planned comparisons with paired samples $t$ tests revealed greater accuracy for FAF compared with AAA $\left(t_{(35)}=5.3, p<0.001\right)$ and AFA $\left(t_{(35)}=6.5, p<0.001\right)$; and faster RT for correct FAF trials compared with correct AAA $\left(t_{(35)}=2.1, p<05\right)$ and correct AFA trials $\left(t_{(35)}=2.3, p<0.05\right)$. No differences were observed in performance when matching anonymous faces for accuracy $\left(t_{(35)}\right.$ $=-0.3, p=0.78)$ or $\mathrm{RT}\left(t_{(35)}=0.3, p=0.77\right)$. In all cases, two-tailed $p$ values are reported.

\section{Neuroimaging}

First, we examined sustained faces n-back task performance relative to fixation. A significant pattern of activity dissociated the task from the fixation baseline ( $p=0.002$; Fig. $2 A$; Table 1$)$. Sustained task performance over the block was associated with increased BOLD signal in bilateral, lateral prefrontal and parietal brain regions, anterior insula, dorsal anterior cingulate, and the lateral fusiform gyrus. Conversely, fixation was associated with 
Table 1. Peak activation coordinates

\begin{tabular}{|c|c|c|c|c|}
\hline \multirow[b]{2}{*}{ Region } & \multicolumn{3}{|c|}{ Coordinates } & \multirow[b]{2}{*}{ BSR } \\
\hline & $x$ & $y$ & $Z$ & \\
\hline \multicolumn{5}{|l|}{ Faces n-back task > rest } \\
\hline Occipital fusiform cortex & -22 & -82 & -14 & 10.14 \\
\hline Occipital fusiform cortex & 14 & -86 & -18 & 8.77 \\
\hline Fusiform face area & 42 & -48 & -26 & 8.11 \\
\hline Dorsal anterior cingulate & -2 & 6 & 58 & 7.83 \\
\hline Precentral gyrus & -44 & 2 & 36 & 7.51 \\
\hline Fusiform face area & -36 & -46 & -26 & 7.47 \\
\hline Anterior insula & 30 & 24 & 2 & 7.46 \\
\hline Middle frontal gyrus & 48 & 34 & 32 & 6.72 \\
\hline Intaparietal sulcus & -30 & -58 & 42 & 6.33 \\
\hline Intaparietal sulcus & 38 & -48 & 40 & 6.33 \\
\hline Anterior insula & -30 & 24 & 4 & 6.32 \\
\hline Inferior temporal gyrus & -66 & -38 & -18 & 5.63 \\
\hline Middle frontal gyrus & -50 & 24 & 32 & 5.11 \\
\hline Frontal pole & -4 & 66 & -10 & 5.00 \\
\hline Middle frontal gyrus & 42 & 2 & 58 & 4.33 \\
\hline Middle temporal gyrus & 68 & -38 & -12 & 4.20 \\
\hline Thalamus & -14 & -26 & 20 & 3.68 \\
\hline Precuneus & 8 & -76 & 50 & 3.28 \\
\hline \multicolumn{5}{|l|}{ Rest $>$ faces n-back task } \\
\hline Ventromedial prefrontal cortex & 12 & 52 & -4 & -12.40 \\
\hline Parahippocampal cortex & -28 & -42 & -16 & -9.41 \\
\hline Posterior insula & -42 & -18 & -4 & -8.57 \\
\hline Posterior middle cingulate & 16 & -16 & 50 & -8.50 \\
\hline Posterior insula & 44 & -14 & 2 & -8.26 \\
\hline Retrosplenial cortex & -14 & -60 & 12 & -7.64 \\
\hline Posterior cingulate & 12 & -32 & 42 & -7.03 \\
\hline Anterior temporal lobe & 42 & -2 & -32 & -5.47 \\
\hline Parahippocampal cortex & 26 & -44 & -14 & -5.17 \\
\hline Occipital pole & -30 & -100 & -10 & -5.09 \\
\hline Lateral occipital cortex & -34 & -88 & 22 & -4.85 \\
\hline Middle occipital gyrus & 42 & -80 & 24 & -4.60 \\
\hline Supramarginal gyrus & -60 & -36 & 30 & -4.20 \\
\hline Cerebellum & 26 & -76 & -44 & -3.33 \\
\hline Anterior temporal lobe & -34 & 2 & -36 & -3.24 \\
\hline
\end{tabular}

many regions of the default network, including MPFC, PCC, inferior parietal lobule, medial temporal lobes, and posterior insula.

We next examined the pattern of neural activity associated with perceiving a famous face for the first time (in the experimental session), relative to seeing an anonymous face for the first time. A significant pattern of activity dissociated these trials ( $p=$ 0.002; Fig. $2 B$; Table 2). Transient increases in activity while viewing the first instance of a famous face were observed in MPFC, PCC, anterior temporal lobes, hippocampus, anterior insula, ventral temporal lobe, and left prefrontal cortex. In contrast, viewing an anonymous face for the first time showed relatively more activity in the extended frontoparietal control network (Vincent et al., 2008; Spreng et al., 2010), including middle frontal gyrus and rostrolateral prefrontal cortex, the anterior extent of the inferior parietal lobule, inferior lateral temporal cortex, and occipital cortex.

We then examined brain activity during the face triplets for the AAA, AFA, and FAF conditions. Only correct trials were included in this analysis. In this data-driven analysis, we found that the FAF condition dissociated from the AAA and AFA conditions, which covaried together $(p<0.02$; Fig. $2 C$; Table 3$)$. Matching famous faces engaged MPFC, PCC, hippocampus, anterior temporal lobe, and parahippocampal cortex. Matching anonymous faces, in contrast, engaged dorsal anterior cingulate, rostrolateral prefrontal cortex, middle frontal gyrus, insula, su-
Table 2. Peak activation coordinates

\begin{tabular}{|c|c|c|c|c|}
\hline \multirow[b]{2}{*}{ Region } & \multicolumn{3}{|c|}{ Coordinates } & \multirow[b]{2}{*}{ BSR } \\
\hline & $x$ & $y$ & $z$ & \\
\hline \multicolumn{5}{|l|}{ Famous face $>$ anonymous face } \\
\hline Posterior cingulate cortex & -6 & -58 & 14 & 7.19 \\
\hline Ventromedial prefrontal cortex & -6 & 52 & -14 & 7.10 \\
\hline Anterior insula & -36 & 26 & 0 & 5.77 \\
\hline Parahippocampus & 28 & -30 & -20 & 5.41 \\
\hline Inferior frontal gyrus & -44 & 18 & 22 & 5.35 \\
\hline Anterior temporal lobe & -62 & -4 & -26 & 5.22 \\
\hline Fusiform gyrus & -34 & -32 & -20 & 4.80 \\
\hline Parahippocampus & -20 & -40 & -20 & 4.53 \\
\hline Fusiform gyrus & 34 & -44 & -24 & 4.49 \\
\hline Precentral gyrus & -58 & 0 & 36 & 4.43 \\
\hline Putamen & 14 & 6 & -8 & 4.40 \\
\hline Retrosplenial cortex & -18 & -40 & -12 & 4.29 \\
\hline Hippocampus & -30 & -22 & -20 & 4.05 \\
\hline Anterior temporal lobe & 50 & -8 & -16 & 3.97 \\
\hline Anterior insula & 38 & 28 & -2 & 3.85 \\
\hline Hippocampus & 26 & -18 & -16 & 3.81 \\
\hline Dorsomedial prefrontal cortex & -8 & 52 & 40 & 3.75 \\
\hline \multicolumn{5}{|l|}{ Anonymous face $>$ famous face } \\
\hline Anterior inferior parietal lobule & 52 & -48 & 44 & -10.21 \\
\hline Anterior inferior parietal lobule & -48 & -44 & 42 & -9.36 \\
\hline Precuneus & 12 & -72 & 42 & -8.91 \\
\hline Cerebellum & -30 & -66 & -38 & -8.34 \\
\hline Middle temporal gyrus & 58 & -22 & -20 & -7.92 \\
\hline Orbitofrontal gyrus & 12 & 26 & -16 & -7.90 \\
\hline Frontal pole & 44 & 50 & 2 & -7.64 \\
\hline Middle frontal gyrus & 30 & 10 & 60 & -7.05 \\
\hline Middle cingulate & 4 & -38 & 44 & -6.53 \\
\hline Frontal pole & -36 & 58 & -16 & -5.71 \\
\hline Occipital cortex & -12 & -78 & 0 & -5.67 \\
\hline Middle frontal gyrus & -36 & 10 & 58 & -5.29 \\
\hline Inferior temporal gyrus & -52 & -30 & -22 & -5.08 \\
\hline Caudate & -22 & 12 & 18 & -3.66 \\
\hline Precentral gyrus & -62 & 10 & 12 & -3.26 \\
\hline Thalamus & 14 & -8 & 10 & -3.09 \\
\hline
\end{tabular}

pramarginal gyrus, right temporoparietal junction, and other regions.

In a final control analysis, we used a median split of RT to divide the AAA, AFA, and FAF triplet conditions. Again, only accurate trials were included. This analysis was conducted to demonstrate that greater default network engagement during FAF was not an artifact of the faster RT on these trials. If trial-wise release from task were to account for the default network activity, than we would expect greater default network activity for the faster AAA and AFA conditions than the slower FAF, which were significantly different $\left(t_{(35)}=-15.0, p<0.001 ; t_{(35)}=-17.5\right.$, $p<0.001$, respectively). Additionally, we would not expect to see differences in default network activity for the RT-matched slow AAA, AFA, and FAF conditions, which were not significantly different from each other $\left(F_{(2,34)}=0.13, p=0.88\right)$. We found that RT did not explain differences in default network activity. Once again, FAF was dissociated from AAA and AFA, with high and low RT conditions covarying together. Both high and low RT conditions for the famous face-match trials engaged default network brain regions ( $p<0.05$; Fig. 3 ), consistent with the prior triplet analysis.

\section{Discussion}

We developed a novel faces n-back working memory task to investigate whether goal-congruent activation of the default network was associated with better performance on an executive control task. Transient default network activity has been associ- 
Table 3. Peak activation coordinates

\begin{tabular}{|c|c|c|c|c|}
\hline \multirow[b]{2}{*}{ Region } & \multicolumn{3}{|c|}{ Coordinates } & \multirow[b]{2}{*}{ BSR } \\
\hline & $x$ & $y$ & $z$ & \\
\hline \multicolumn{5}{|l|}{$\begin{array}{l}\text { Famous face-match triplet }> \\
\text { anonymous face-match triplets }\end{array}$} \\
\hline Hippocampus & 28 & -10 & -18 & 5.36 \\
\hline Posterior cingulate & -4 & -56 & 14 & 5.27 \\
\hline Fusiform gyrus & -30 & -34 & -24 & 5.27 \\
\hline Temporal pole & -46 & 20 & -36 & 5.14 \\
\hline Ventromedial prefrontal cortex & -6 & 50 & -18 & 4.91 \\
\hline Dorsomedial prefrontal cortex & -8 & 58 & 30 & 3.82 \\
\hline Hippocampus & -30 & -12 & -18 & 3.48 \\
\hline Lateral occipital cortex & -38 & -70 & 18 & 3.47 \\
\hline Lateral temporal pole & 66 & -6 & -24 & 3.25 \\
\hline \multicolumn{5}{|l|}{$\begin{array}{c}\text { Anonymous face-match triplets }> \\
\text { famous face-match triplet }\end{array}$} \\
\hline Inferior temporal gyrus & 54 & -24 & -34 & -5.72 \\
\hline Supplementary motor area & 10 & -4 & 62 & -5.58 \\
\hline Anterior insula & 46 & 10 & 2 & -5.34 \\
\hline Cuneus & -8 & -86 & 24 & -5.12 \\
\hline Temporal pole & -30 & 20 & -46 & -5.05 \\
\hline Orbitofrontal cortex & 18 & 46 & -24 & -5.03 \\
\hline Supramarginal gyrus & 58 & -38 & 52 & -4.97 \\
\hline Cerebellum & 10 & -60 & -20 & -4.80 \\
\hline Frontal pole & 28 & 48 & 24 & -4.72 \\
\hline Dorsal anterior cingulate & 6 & 20 & 34 & -4.71 \\
\hline Frontal eye field & -28 & 4 & 56 & -4.55 \\
\hline Middle cingulate & 4 & -8 & 44 & -4.42 \\
\hline Precuneus & 12 & -70 & 44 & -4.42 \\
\hline Temporal parietal junction & 50 & -44 & 16 & -4.42 \\
\hline Insula & -42 & 6 & 8 & -4.36 \\
\hline Cerebellum & -36 & -86 & -36 & -4.18 \\
\hline Thalamus & 8 & -12 & 16 & -4.12 \\
\hline Inferior temporal gyrus & -50 & -20 & -34 & -3.87 \\
\hline Superior parietal lobule & -18 & -44 & 56 & -3.54 \\
\hline Temporal parietal junction & -52 & -50 & 0 & -3.44 \\
\hline Lateral occipital cortex & 54 & -68 & -8 & -3.31 \\
\hline
\end{tabular}

ated with off-task behaviors, such as mind wandering and linked to reduced cognitive control performance (Weissman et al., 2006; Mason et al., 2007; Christoff et al., 2009). This is perhaps not surprising as mind-wandering is typically characterized by focusing on internal representations of oneself, other people, or remembering or imagining personal events (Smallwood, 2013), thereby drawing attentional resources away from external, taskrelevant stimuli (Baird et al., 2014). Prior studies of cognitive control typically use stimuli that do not activate long-term memory or are devoid of personal significance. Few studies have examined default network activity when access to internal representations is relevant to task performance. Here we embedded trials known to engage the default network, viewing famous faces (Leveroni et al., 2000; Eger et al., 2005; Ross and Olson, 2012), within a continuous working memory paradigm known to activate brain regions implicated in cognitive control (Owen et al., 2005). Our aim was to test whether transient increases in default network activity would facilitate working memory performance when access to internal mental representations is congruent with task goals.

Behaviorally, n-back task performance was better for famous than anonymous face-match triplets. This is consistent with evidence that visual working memory is enhanced for stimuli with robust long-term memory representations (Jackson and Raymond, 2008). To investigate interactions between default network activity and control processing at the level of the brain, we first conducted confirmatory analyses to evaluate the main effects of our primary task manipulations for, (1) sustained working memory activity, and, (2) viewing famous faces. Sustained n-back task performance demonstrated bilateral increases in intraparietal sulcus, the putative frontal eye fields, ventral precentral sulcus, lateral prefrontal regions, dorsal anterior cingulate, and anterior insula, compared with fixation, consistent with previous neuroimaging studies of nonverbal n-back performance (Fig. 2A; Owen et al., 2005). Additional activity was observed in ventral visual association cortices corresponding to the putative fusiform face area. To examine transient activity associated with viewing famous faces, we contrasted activity when participants viewed the first instances of famous and anonymous faces. Significant increases were observed within MPFC, PCC, lateral and medial temporal lobes, and the left inferior frontal gyrus for famous compared with anonymous face viewing, consistent with previous findings (Fig. 2B; Leveroni et al., 2000; Natu and O'Toole, 2011). In contrast, viewing anonymous faces revealed greater activity in the frontoparietal control network (Vincent et al., 2008; Spreng et al., 2010), including the middle frontal gyrus and anterior extent of the inferior parietal lobule (Fig. 2B). This increased activation in frontoparietal control regions raises the possibility that working memory for anonymous faces requires greater top-down control processes than famous face matching, where performance is supported by bottom-up access to longterm memory representations.

Finally, we examined patterns of brain activity that distinguished the famous and anonymous face-match conditions. Significantly greater default network activity was observed for the famous face-match triplet. This observation is consistent with our prediction that greater activity in the default network would correspond with better executive control performance. These results directly contradict the prevailing "task-negative" network view (for review, see Spreng, 2012), which suggests that recruitment of the default network during controlled processing is associated with off-task behaviors, poor task performance, and is a putative biomarker of cognitive dysfunction and brain disease (Anticevic et al., 2012; Whitfield-Gabrieli and Ford, 2012; Andrews-Hanna et al., 2014). An alternate explanation might be that the famous face-match triplet condition is easier and thereby engages the default network to a greater degree. From this perspective, faster RTs may have provided greater trial-wise opportunities to engage in off-task behaviors, consistent with the task-negative view of default network activation. Conceptually, this is an unlikely explanation because the n-back paradigm is a continuous performance task and provides no release from controlled processing demands regardless of trial-wise RTs. Empirically, RT did not emerge as a significant factor in the median split RT analysis (Fig. 3) where high- and low-RT famous face-match trials covary together and engage the default network. Familiarity enhances working memory under conditions where stored personal semantic information can be accessed to support online maintenance (Gobbini and Haxby, 2007; Jackson and Raymond, 2008). This behavioral facilitation effect aligns with neuroimaging evidence that viewing familiar relative to unfamiliar faces activates regions of the default network (Leveroni et al., 2000; Shah et al., 2001; Eger et al., 2005; Ross and Olson, 2012). This activity is consistent with a role for the default network in mnemonic, social, and self-referential processing (Andrews-Hanna et al., 2014). To reconcile the task-negative view with the current findings, we argue that increased default network activation can support cognitive control, but only when access to stored mnemonic representations is congruent with the specific demands of the task. Otherwise, activation of the default network, which may 
A

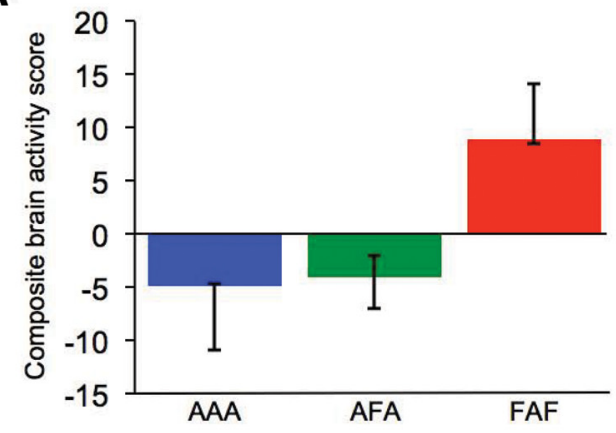

C

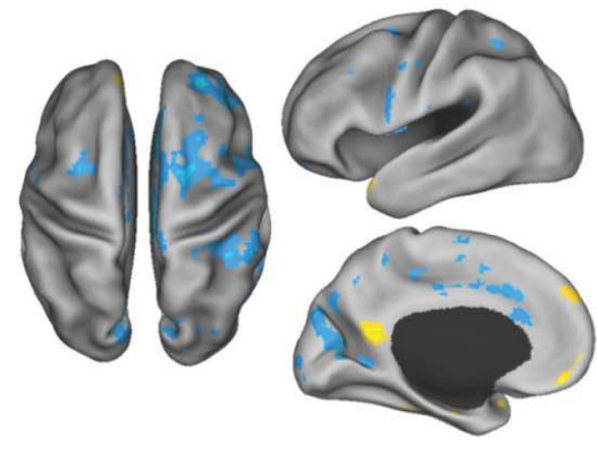

B
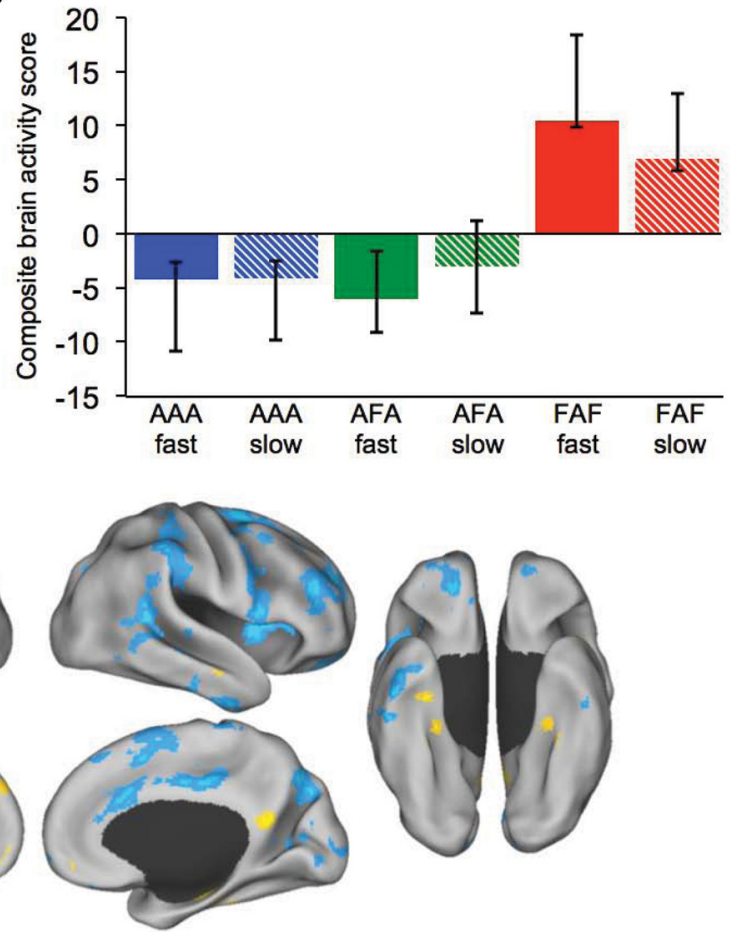

Figure 3. Matching anonymous and famous faces. $A$, Composite brain activity scores for the anonymous face-matching triplets (AAA/AFA) and famous face-matching triplets (FAF; see Fig. 2 C for corresponding brain activity map). $\boldsymbol{B}$, Composite brain activity scores in the median RT split analysis of the anonymous and famous face-matching triplets. For both ( $\boldsymbol{A})$ and ( $\boldsymbol{B})$, anonymous face-matching conditions covary together and are dissociated from famous face-matching conditions. No differences were observed within condition by RT. Confidence intervals calculated from the bootstrap resampling. C, Brain activity for the median RT split analysis during the triplets for famous face-matching (warm colors) and anonymous face-matching (cool colors) conditions.

signal off-task behaviors, such as mind wandering, would detract from controlled processing.

These findings demonstrate that goal-congruent default network activation facilitates task performance during continuous executive control demand where mnemonic processes may guide behavior. Smallwood et al. (2013a) demonstrated that the default network can be active under situations where external processing is compromised, or when mnemonic processing was facilitative, depending upon whether perception or memory were aligned with the goals of the task. Supporting the action-perception decoupling hypothesis, default network engagement is associated with better performance on tasks that do not require access to immediate perceptual information (Smallwood, 2013; Smallwood et al., 2013a). We extend this model, demonstrating that access to long-term memory representations, over and above working memory per se, engages the default network in the service of externally directed cognitive control.

There is growing evidence of dynamic functional coupling between default and cognitive control brain regions as task demands alternate between externally and internally directed attention as well as during the transition from rest to task performance (Spreng et al., 2010; Bluhm et al., 2011; Spreng and Schacter, 2012; Cocchi et al., 2013; Cole et al., 2013). Here we extend our understanding of the role of the default network in cognitive control by demonstrating that transient increases in activation, not only coupling, can facilitate controlled processing, when access to internal mental representations is congruent with the goals of the task. This model supports the hypothesis that internally and externally directed cognitive processes interact in a facilitative manner to support goal-directed cognition (Dixon et al., 2014).
The famous faces n-back task does not explicitly cue retrieval, relying instead on spontaneous or incidental activation of internal mental representations (Todorov et al., 2007). It is unclear whether context-relevant activation of default brain regions during cognitive control may occur without conscious awareness or whether active, intentional retrieval is necessary. A study of transitive reasoning found increased connectivity between default and frontoparietal control regions, but only when participants consciously activated a previously learned sequence structure (Rogers et al., 2010). Similarly, during a social working memory task, internal representations were explicitly cued (i.e., knowledge of a friend's personality traits) and increased executive and default network activation was also reported (Meyer et al., 2012). In a recent review, intentionality was also identified as a critical factor guiding interactions between internally and externally directed cognitive processes (Dixon et al., 2014). Our data suggest that automatic retrieval of stored representations may be sufficient to show default engagement during cognitive control tasks. Further study of intentional versus spontaneous engagement of default network regions in the service of goal-directed cognition is an important area of future research.

These findings provide a more comprehensive account of default and cognitive control interactions. Recruitment of default network regions during controlled processing is dependent on the congruence between external task goals and activation of internal mental representations. Many cognitive control paradigms include stimuli (e.g., shapes, spatial locations, and letters) that minimally engage stored mnemonic representations; indeed, these have previously been viewed as confounds. On these tasks, access to, or activation of, internal representational knowledge is task-irrelevant and detrimental to ongoing cognitive control. 
Goal-pursuit in the real world rarely involves processing novel information or stimuli devoid of personal meaning. Outside of the laboratory, humans pursue goals by continuously accessing stored representational knowledge about past experiences, current motivations, future plans, and the social milieu. Here we argue that contextually relevant engagement of default-network brain regions is a critical mechanism facilitating this ongoing dialogue between pursuit of external goals and internal representations.

\section{References}

Andrews-Hanna JR, Smallwood J, Spreng RN (2014) The default network and self-generated thought: component processes, dynamic control, and clinical relevance. Ann N Y Acad Sci 1316:29-52. CrossRef Medline

Anticevic A, Cole MW, Murray JD, Corlett PR, Wang XJ, Krystal JH (2012) The role of default network deactivation in cognition and disease. Trends Cogn Sci 16:584-592. CrossRef Medline

Baird B, Smallwood J, Gorgolewski KJ, Margulies DS (2013) Medial and lateral networks in anterior prefrontal coretx support meta cognitive ability for memory and perception. J Neurosci 33:16657-16665. CrossRef Medline

Baird B, Smallwood J, Lutz A, Schooler JW (2014) The decoupled mind: mind-wandering disrupts cortical phase-locking to perceptual events. J Cogn Neurosci, in press. CrossRef

Bluhm RL, Clark CR, McFarlane AC, Moores KA, Shaw ME, Lanius RA (2011) Default network connectivity during a working memory task. Hum Brain Mapp 32:1029-1035. CrossRef Medline

Christoff K, Gordon AM, Smallwood J, Smith R, Schooler JW (2009) Experience sampling during fMRI reveals default network and executive system contributions to mind wandering. Proc Natl Acad Sci U S A 106: 8719-8724. CrossRef Medline

Cocchi L, Zalesky A, Fornito A, Mattingley JB (2013) Dynamic cooperation and competition between brain systems during cognitive control. Trends Cogn Sci 17:493-501. CrossRef Medline

Cole MW, Reynolds JR, Power JD, Repovs G, Anticevic A, Braver TS (2013) Multi-task connectivity reveals flexible hubs for adaptive task control. Nat Neurosci 16:1348-1355. CrossRef Medline

Dixon ML, Fox KC, Christoff K (2014) A framework for understanding the relationship between externally and internally directed cognition. Neuropsychologia 62:321-330. CrossRef Medline

Eger E, Schweinberger SR, Dolan RJ, Henson RN (2005) Familiarity enhances invariance of face representations in human ventral visual cortex: fMRI evidence. Neuroimage 26:1128-1139. CrossRef Medline

Gobbini MI, Haxby JV (2007) Neural systems for recognition of familiar faces. Neuropsychologia 45:32-41. CrossRef Medline

Jackson MC, Raymond JE (2008) Familiarity enhances visual working memory for faces. J Exp Psychol Hum Percept Perform 34:556-568. CrossRef Medline

Krishnan A, Williams LJ, McIntosh AR, Abdi H (2011) Partial least squares (PLS) methods for neuroimaging: a tutorial and review. Neuroimage 56: 455-475. CrossRef Medline

Leveroni CL, Seidenberg M, Mayer AR, Mead LA, Binder JR, Rao SM (2000) Neural systems underlying the recognition of familiar and newly learned faces. J Neurosci 20:878-886. Medline

Mason MF, Norton MI, Van Horn JD, Wegner DM, Grafton ST, Macrae CN
(2007) Wandering minds: the default network and stimulus-independent thought. Science 315:393-395. CrossRef Medline

Mazaika PK, Hoeft F, Glover GH, Reiss AL (2009) Methods and software for fMRI analysis for clinical subjects. Neuroimage 47:S58. CrossRef

Meyer ML, Spunt RP, Berkman ET, Taylor SE, Lieberman MD (2012) Evidence for social working memory from a parametric functional MRI study. Proc Natl Acad Sci U S A 109:1883-1888. CrossRef Medline

Natu V, O’Toole AJ (2011) The neural processing of familiar and unfamiliar faces: a review and synopsis. Br J Psychol 102:726-747. CrossRef Medline

Owen AM, McMillan KM, Laird AR, Bullmore E (2005) N-back working memory paradigm: a meta-analysis of normative functional neuroimaging studies. Hum Brain Mapp 25:46-59. CrossRef Medline

Rogers BP, Avery SN, Heckers S (2010) Internal representation of hierarchical sequences involves the default network. BMC Neurosci 11:54. CrossRef Medline

Ross LA, Olson IR (2012) What's unique about unique entities? An fMRI investigation of the semantics of famous faces and landmarks. Cereb Cortex 22:2005-2015. CrossRef Medline

Shah NJ, Marshall JC, Zafiris O, Schwab A, Zilles K, Markowitsch HJ, Fink GR (2001) The neural correlates of person familiarity: a functional magnetic resonance imaging study with clinical implications. Brain 124:804-815. CrossRef Medline

Smallwood J (2013) Distinguishing how from why the mind wanders: a process-occurrence framework for self-generated mental activity. Psychol Bull 139:519-535. CrossRef Medline

Smallwood J, Tipper C, Brown K, Baird B, Engen H, Michaels JR, Grafton S, Schooler JW (2013a) Escaping the here and now: evidence for a role of the default mode network in perceptually decoupled thought. Neuroimage 69:120-125. CrossRef Medline

Smallwood J, Gorgolewski KJ, Golchert J, Ruby FJ, Engen H, Baird B, Vinski MT, Schooler JW, Margulies DS (2013b) The default modes of reading: modulation of posterior cingulate and medial prefrontal cortex connectivity associated with comprehension and task focus while reading. Front Hum Neurosci 7:734. CrossRef Medline

Spreng RN (2012) The fallacy of a "task-negative" network. Front Psychol 3:145. CrossRef Medline

Spreng RN, Schacter DL (2012) Default network modulation and largescale network interactivity in healthy young and old adults. Cereb Cortex 22:2610-2621. CrossRef Medline

Spreng RN, Stevens WD, Chamberlain JP, Gilmore AW, Schacter DL (2010) Default network activity, coupled with the frontoparietal control network, supports goal-directed cognition. Neuroimage 53:303-317. CrossRef Medline

Todorov A, Gobbini MI, Evans KK, Haxby JV (2007) Spontaneous retrieval of affective person knowledge in face perception. Neuropsychologia 45 : 163-173. CrossRef Medline

Vincent JL, Kahn I, Snyder AZ, Raichle ME, Buckner RL (2008) Evidence for a frontoparietal control system revealed by intrinsic functional connectivity. J Neurophysiol 100:3328-3342. CrossRef Medline

Weissman DH, Roberts KC, Visscher KM, Woldorff MG (2006) The neural bases of momentary lapses in attention. Nat Neurosci 9:971-978. CrossRef Medline

Whitfield-Gabrieli S, Ford JM (2012) Default mode network activity and connectivity in psychopathology. Annu Rev Clin Psychol 8:49-76. CrossRef Medline 